\title{
A Practical Solution for Pollution Management and Waste Disposal Issue in Urban Environments
}

\author{
${ }^{1}$ Laura Schaefer and ${ }^{2}$ Arvind Atreya \\ 1,2 Department of Mechanical Engineering, Rice University, Main St., Houston, TX, USA \\ ${ }^{1}$ laurascha@rice.edu, ${ }^{2}$ arvindatr@rice.edu
}

\begin{abstract}
ArticleInfo
Journal of Machine and Computing (http://anapub.co.ke/journals/jmc/jmc.html)

Doi : https://doi.org/10.53759/7669/jmc202101006

Received 17 October 2020; Revised form 25 November 2020; Accepted 25 December 2020;

Available online 05 January 2021.

(C)2021 The Authors. Published by AnaPub Publications.

This is an open access article under the CC BY-NC-ND license. (http://creativecommons.org/licenses/by-nc-nd/4.0/)

Abstract - In this research contribution, a practical solution is presented for pollution management and waste disposal issue in urban environments. This research applies disposal techniques and proposes adequate optimal usage of rubbish drums and trashcan available in public and private sites. The wide-range and consistent application of advance biomaterials and recycling equipment has been considered in this research. The flow of information and training of the wide-range application of novel methods and techniques calls for the introduction and production of state-of-the-art policies and technologies to develop the execution and implementation of effective waste management systems that will contribute to safer and cleaner ecosystems in developing nations. This paper presents the waste management chart with steps to follow to ensure that the solution has been applied effectively,
\end{abstract}

Keyword - Biomaterials, Pollution Management, Waste Disposal, Urban Environments.

\section{INTRODUCTION}

Water disposal and crude disposal methods and techniques have established a critical case of pollution on the environment hence causing significant havoc in developing urban environments. This has led to the degradation of biotic and abiotic components of the ecosystem in ecological systems. Poor industrial systems for waste disposal, including ineffective and indiscriminate domestic litter disposal practices have been determined and proved significant in rural environments, urban centers, and semi-urban environments in developing countries. Resultantly, these have contributed to ecological deterioration and environmental pollution in industries. The core purpose of this was the deficiency of information and inadequate modern waste disposal systems and facilities.

To mitigate this issue, fluid and solid bio-wastes and their disposal techniques have slowly become significant as a treatment to the ecosystems in developing nations since they significantly shift towards the aspect of industrialization. Swift rural to urban shift and dense populations in developed countries have also intensified and added to the aspect of pollution in the ecosystem. Insufficient information and inadequate resources e.g. policy execution capacity, technology finance and facility evaluation are limiting factors that have been witnesses to influence the techniques and solutions meant to mitigate the issue of pollution management due to industrial and domestic bio-wastes.

Effective waste management techniques and systems of fluid and solid waste disposals approaches are needed in these developing nations [1]. Effective methods and facilities suitable for ecological protection have to be introduced and applied in the various polluted environments. In developing countries, massive bio-wastes, in general, incorporate fecal, urinary, leather, hides, animal skin, bones, blood, glass, plastics, mire, dusts, used tire, vehicle scraps, polythene bags, and food biomaterials. When all these bio-wastes are ineffectively disposed, which is typically the case in many developing countries, they pose thereat to wildlife, vegetable, land, water air and humans.

Disease and sickness epidemics normally occur when unwanted substances e.g. garbage bio-wastes and sewage are ineffectively disposed and improperly managed [2]. The present methods of pollution management are ineffective. The situation of poor waste management is typically lower (due to less waste congestion) than in urban environments. In that case, the repercussions and impacts are minimal. Moreover, some of these waste forms may not exist in remote rural i.e. vehicle scrapes, tires, glass etc. Whereas solid bio-wastes might be found in rural environments, toxic inorganic chemicals and waste industrial bio-materials are rare in these ecosystems since rural areas are typically away from industrial areas, mineral exploration zones and manufacturing factories. Nonetheless, ecosystems of watersheds, coastal creeks, shorelines and inland waterways close to these anthropogenic activities are at significant risks of degradation and pollution.

This research contribution focuses on presenting a practical solution on pollution and waste disposal issues. In this paper, an analysis of waste disposal techniques, which could be applied in developing countries, is done. A proposal on the 
wide-range application of recyclable bio-materials, including the flow of training and information regarding the usage of novel techniques and methods, including the necessity for introduction and production of effective policies and technologies is also recommended.

The ecosystem is rapidly transforming through the developments in industrial revolution and the usage of fossil fuels call for alarm on the issue of pollution. Industrial activities have been considered as a major cause of pollution in urban environments [3]. However, this perspective has led to the introduction of sustainable management concepts in industries in developed countries. The concepts imply the continued enhancement of industries in a manner that possess minimal ecological implication on urban environments.

To transform the quality of environments based on the influence pollutants have on the ecosystem, a practical solution is apt. The adaptation of nature and man has presented questions for industrial modes of production concerning the management of pollution. Pollution of major elements in the ecosystem i.e. land, water and air, has reached an alarming limit. Spaces and landscapes are beyond the control of human activities. Human identified and legally safeguarded these natural aspects. Daily industrial activities and working life of humans in urban environments are a critical factor influencing pollution. Some forms of bio-wastes signify a fundamental potential risk to the ecosystem and the health of man. Industries have not fully comprehended this potential threat.

In many developing urban environments, there are minimal or no policies and regulations regarding the management of bio-wastes and pollutants [4]. The amount of bio-wastes has enhanced significantly over the past few decades because of various forms of pesticides, which are applied in agricultural activities and industrial toxic bio-wastes, including cancerogenic bio-materials. Moreover, global warming has come into the effort and facilitating the depletion of the ozone layer, enhancing acidification of the ecosystem with acid rain and advancing the effective of pollution in the environment. Biodiversity loss, soil degradation and deforestation is the consequence of deteriorating ecological situation in various developing countries.

Minimizing pollution and waste disposal is a fundamental objective for sustainable management of bio-wastes in developing countries [5]. Recycling is considered as one of the solutions and methods focused at maximizing the usage of raw bio-materials and energy. In many developing countries, the method of recycling is vital since it enhances the elimination of bio-wastes and pollutants. Significantly, recycling maintains energy and raw bio-materials from useless and discarded products and raw bio-materials. The increment in population and production activities of large quantities of biowastes to landfills seems to become significantly numerous and degrades the ecosystem. Landfills as a result, cover a widerange segment of arable land, which develops in uncontrolled bumps with risky situations and necessitate significant costs in an attempt to eliminate them.

This research focusses on practical remedies and solutions for pollution management and waste disposal management. Section I has shown the significance of minimizing the amount of generated bio-wastes and pollutants while recommending recycling as one of the methods that developing countries can consider for their domestic and industrial activities. The remaining part of the contribution is organized as follows: Section II focusses on the literature review of the previous assumptions. Section III evaluates the biomaterials and methods. Section IV presents the results and discussion of the practical remedies of waste disposal and pollution management for developing countries. Finally, Section V concludes the paper and presents future directions.

\section{LITERATURE REVIEW}

Z. Ulfah and N. Roesa in [6] comment on the Polluter Pays principles, which focus on the management of bio-wastes, reuse of bio-wastes and recycling practices. Apart from that, the principle focus on the separation of the bio-materials that can be recycled from the bio-wastes and utilize the bio-wastes as energy resource development methods and processes of disposing bio-wastes, solutions of unregulated dump and the enhancement of awareness of waste management includes the management of bio-wastes. The ideology of waste management denotes to the activities of monitoring, tracking, disposal, recycling, sorting, transporting and collecting of activities.

G. Bennett in [7] argues that the transportation, treatment and storage of bio-wastes carry significant threats to health and safety of workers in waste plants. System activities including those for preventing bio-wastes by minimizing packaging bio-materials, developing habits of categorizing bio-wastes and reducing bio-wastes signify waste management schemes. The strategies of waste management provide engineering firms with advent of formal legal techniques and mechanisms e.g. the acquisition of expertize when it comes to the management of bio-wastes. Secondly, it enhances the acquisition and enhancement of training and education of individuals who manage bio-wastes; establishment of bodies and entities obliged for the expansion of educational programs and training programs for the management of bio-wastes.

J. Kára, E. Janča and D. Herák in [8] confirm that various means of intensifying the usage of bio-wastes, to enhance the quality of manufactured raw bio-materials and developing the number of participant in the process of recycling amount to significant protection of the environment. Most developing countries acknowledge the approaches placed by the European Union connecting to the structuring of novel technologies for recycling, and optimization of systems of sorting and collecting bio-wastes. Moreover, it leads the reduction of external expenses of re-usage of bio-wastes, computerized frameworks of managing bio-wastes and exchanging or selling of scrap bio-materials.

U. Mohamed Faizal, R. Jayachitra, P. Vijayakumar and M. Rajasekar in [9] argue that the biggest issue is the collection of bio-wastes for the purposes of recycling i.e. sorting of bio-wastes since some procedures have to be done manually 
hence it enhances the expenses of recycling. However, there are issues with garbage categorization; which means that PET bottles cannot be categorized the same as PVC containers, which also means that they cannot be grouped together. As an ultimate remedy for environmental protection from bio-wastes, packaging or usage of products, which are biodegradable and the ones that do not release toxins to the air is vital.

In [10], a case of a customer selecting products for purchasing has been discussed. From the case, it is seen that the products with excessive packaging do not just pollute the air, but it incorporates the prices that has to be payed and placed for a 30-gram package. The packages hold about 60 grams of visual misleading leads. The analysis consider a case of Japan introducing rules on recycling back in the late 1970s and presently, there are about 40 waste categories. Each Japan resident has received instructions concerning the processes for waste sorting. There are instructions that guide how you use personal items and classify the ones that have to be burned or recycled.

In the same research, it is seen that the products can be eliminated from packaging and proceed to the dumping of plastics into the groups of smaller metals and plastic. Japan, with a population of about 127 million residents, and about 340 individuals in a single square kilometer, the country minimizes the use of land of waste disposal. In major cities of the work, there are about $4 \mathrm{~kg}$ bio-wastes in a capita in a day. Therefore, with the increased population and the present standard of living, bio-wastes have increased significantly.

P. Palaniswamy D, R. Ramesh G, S. Sri Pradeep M and R. Ranjith Raja S in [11] founded that the world annually generate approximately 400 million tons of bio-wastes. The radiochemical industry and the bio-wastes from the military sector incorporate bio-materials that are hazardous to the environment. The production of these bio-wastes can happen in destruction and combat of chemical plants during natural disasters, accidents and during transportation. Dangerous and harmful contaminants working ecosystem incorporate physical (vibrations, noise, dusts, and solid bio-wastes); chemical (waste, dust, fumes, vapors, gases, and aerosols); radiation (x-ray, ultrasound, laser, radar, infrared, oils, and ionization) and biological (rodents, insects, parasites, fungi, molds, bacteria, viruses).

Z. Yuan, J. Shi, H. Wu, L. Zhang and J. Bi in [12] argue that anthropogenic substance get into the environment through various ways. Waste liquids are discharged into underground basins and waterways. Solid bio-wastes are stored in special barriers and landfills in abandoned mineral sites. The sector of agriculture utilizes pesticides and fertilizers (approximately 70 thousand various hazardous and harmful substances, and this list is supplemented yearly with novel 1000 terms. Synthesized novel components, which are not noticed in working ecosystems and living organisms are capable to decompose PVC bio-materials. It is projected that approximately 40, 000, 000 plastic bags and bottle are lost into abandoned nylons and fishing nets.

Due to the increased volume of bio-wastes in the environment, there is need for a practical remedy that industries can use to control the emission of more bio-wastes into the environments. Practical solutions can be applied for developing countries considering their affordability. The presentation of a practical solution of developing countries to control waste disposal and manage pollutants is the major focus of this research contribution. Section III below presents the analysis of advance bio-materials and the methods that can be considered of waste disposal and pollution management.

\section{BIO-MATERIALS AND METHODS}

In this research, past literature assumptions regarding waste disposal and pollution management have been considered. Solid waste in this paper has been considered as the bio-materials that can be discarded because they serve their purposes or are no longer significant. Industrial solid bio-wastes are typically by-products or products of bio-materials from large manufacturing industries and factories. They are typically considered harmful and thus toxic to the biological ecosystem. Domestic solid bio-wastes represent the bio-wastes from domestic activities includes the ones emanating from small-scale activities and households. This activities incorporate animal and human bio-wastes, and garbage from food stuffs.

Fluid bio-wastes represent the bio-materials or liquids and hazardous gas bio-materials [13]. Conglomeration of waste products in towns and cities are typically considered as municipal solid bio-wastes. In developing countries, bio-wastes are featured by the percentage of vegetative matter, which is typically $58 \%$ while other percentages for cans and tins, metals, polythene, wood, termite are considered in the Fig 1 below.

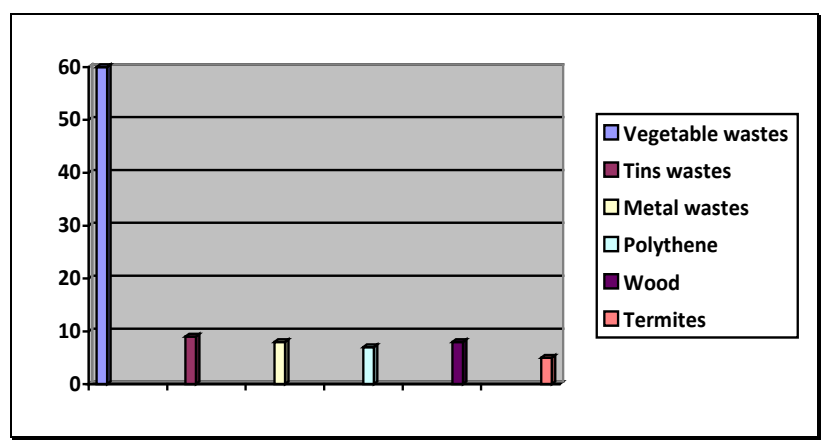

Fig 1: Waste composition percentage in developing nations 
The health and safety factors in the ecosystem are at a risk due to toxic and poisonous condition of hazardous biowastes. This form of bio-wastes can take the shape of sludges, fluids, semi-solids and solids.

\section{A. Waste Management Historical Developments}

Sewages systems and other waste disposal schemes had been structured and elaborate about a century ago [14]. Technological approaches to the processing and management of solid wastes started in the late 90s. Compost, which was watertight cans, started their advent in developed nations sturdier motors were utilized for the collection and transportation of bio-wastes. Significant enhancement in the disposal of wastes techniques and waste treatment processes has been marketed via the construction of garbage incinerators (equipment burning up and minimizing bio-wastes to ash).

A fundamental enhancement in the treatment of solid bio-wastes and practices of waste disposal have been marked based on the structuring of incinerators, which represent the equipment burning up and minimizing ashes and bio-wastes. In the case of England and approximately 15\% of major American cities, solid bio-wastes have been incinerated. Nonetheless, there are many large cities, which are still at their primitive application stages in waste disposal. The advances of technology continued during the early $20^{\text {th }}$ century, incorporating the fundamental developments of compaction trucks, garbage grinders and models of pneumatic gathering.

By around 1950s, it was seen that many available dumping techniques and inefficient incineration of wastes (solid wastes) were causing fundamental pollution issues hence rendering the public to risks. Resultantly, landfills had been formulated to replace available dumping practices and minimize the dependency on incinerations of solid wastes. Novel incinerators of wastes have been formulated to recover heat from biowastes and many devices controlling air pollution have been designed to satisfy stringent disposal standards to enhance the quality of air [15].

Modern management schemes for solid wastes in various countries now concentrate on the practices of waste recycling and waste reduction at its sources, instead of land disposal and incineration. Fig 2 indicates the initial phases in the management of bio-wastes. Effective management of bio-wastes begins by evaluating the various sources and types of biowastes. This is due to the risks on health these bio-wastes pose on the public. These forms of bio-wastes will determine the method recommended for disposal.

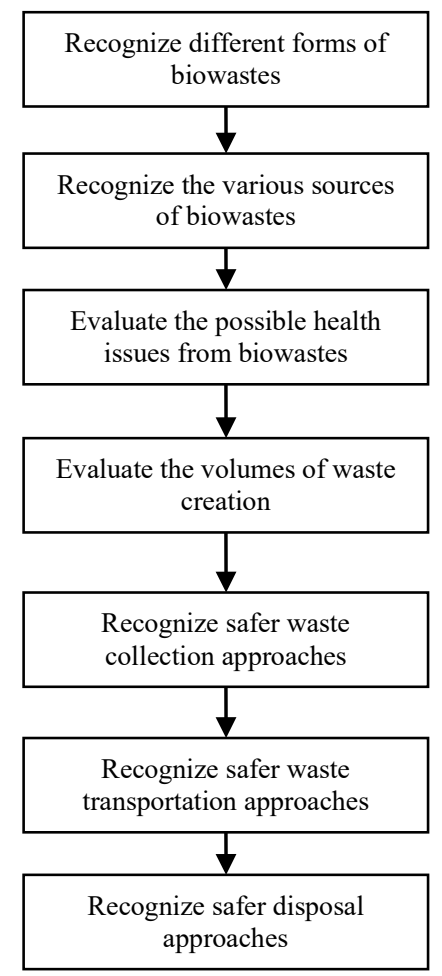

Fig 2: Flow chart steps in the management of bio-wastes

\section{B. Hazardous Bio-wastes and Environmental Issues}

For many decades now, the problems of hazardous bio-wastes in developing countries have been underrated [16]. If no practical remedy is drawn, these bio-wastes can cause hazardous pollution incorporating poor and crude industrial systems of waste disposal, including ineffective and indiscriminate domestic habits of litter disposal in densely population environments. Ineffective collection and disposal techniques of solid bio-wastes are common in most developing urban environments. In many urban environments, bio-wastes are normally generated based on social status of individuals.

The low-income individuals on the other hand, do not typically generate more bio-wastes. The impacts and effects are however, more pronounce in urban environments of the developed countries. This is because of the constant pressure that is exerted by enhanced human activities and the population densities on immediate ecosystems. Ineffective disposal of 
solid bio-wastes can project unsanitary conditions that lead to environmental pollution and disease outbreak e.g. Vectorborne diseases spread by insects and rodents (Fig 3).

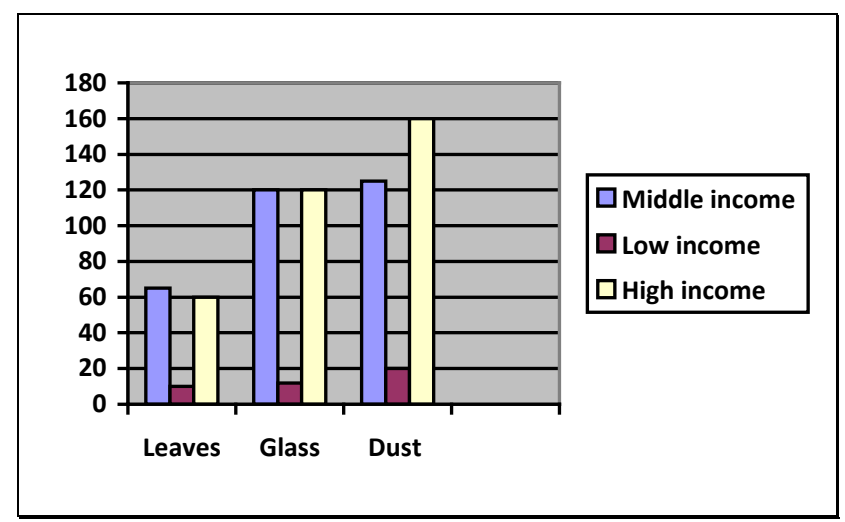

Fig 3: Generation of bio-wastes based on social classes

The obligation of disposing, treating and collecting solid bio-wastes presents significantly complex technical problems. These also pose wide-range socio-cultural, economic and administrative problems, which have to be resolved and managed in developing urban environments. In African countries, e.g. Nairobi, Kenya, the deteriorating environmental conditions affect and influence the methods used for waste disposal [17]. Resultantly, drainage systems are blocked, flooding is evident during heavy rains, groundwater pollution is seen. In the same way, properties and lives are destroyed and lost as a result of the deficiency of appropriate methods of waste management and pollution management.

Apart from Nairobi, Kenya, Ibadan, Nigeria suffers the same fate. Ibadan experience flood disasters that sweep off properties, communities and habitats along the valley plane. Ineffective waste disposal methods alongside deforestation and flooding are some of the major environmental issues that are witnessed in Bauchi, Nigeria. These issues have been by the lack of effective regional and urban planning rules. The lack of basic infrastructures for the disposal of bio-wastes has aggravated the issue of bio-wastes accumulating in Bauchi. The lifespan of pollutants and bio-wastes is a fundamental threat to the management of bio-wastes in developing countries.

Some bio-wastes live more than a century before being properly disposed (See Fig 4). Whenever domestic and industrial bio-wastes contaminate and pollute both underground and critical aquatic resources and surface waste are affected. Other anthropogenic and natural activities, which disrupt and pollute aquatic environments, incorporate land erosion, floods, landfills, gully erosion, oil spills, siltation, eutrophication, algal population explosion, biological pollution, acid rains and sooth deposition. These pose serious risks to coastlines, wetland environments and swamp environment systems, and therefore produce rich biodiversity present in fragile environments.

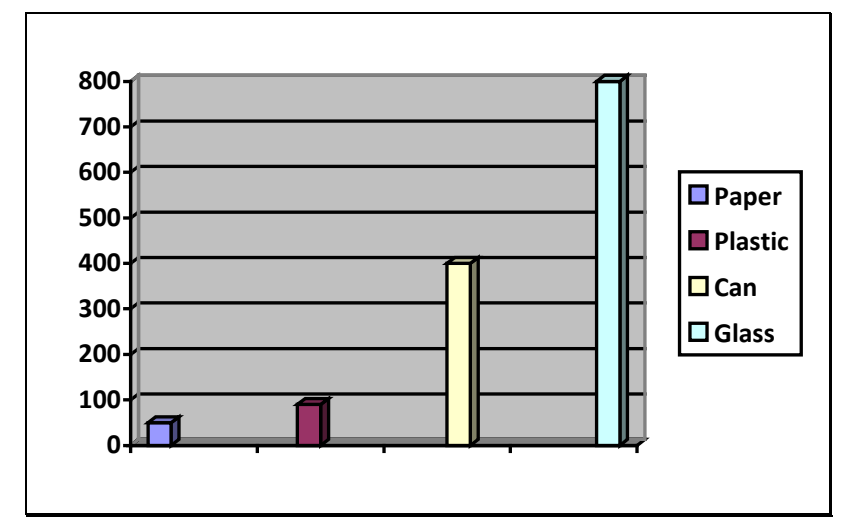

Fig 4: Chart indicating the appropriate years for the decomposition of material

In some developing nations, particular agencies are obliged to monitor and control activities of industrialists. Nonetheless, efforts to effectively and adequately check and curb pollution have proved futile. Hazardous pollutants and bio-wastes are being dumped into seas, open waters and rivers. Dumping over global boarders has also been recounted. As for Koko, bio-wastes dumped into Nigeria's southern part, which is used as an example. This act is not culturally and socially unethical; however, they are ecologically unsound. Both global and local waste disposal guidelines have to be enforced and implemented without compromise or fear. Bribery and incorruption have to be turned over based on authorized inspectors and regulators for the benefit of the ecosystem. Bad habits are also seen when individuals misuse public facilities, neighborhoods, parks, streets and office premises. 


\section{RESULTS AND DISCUSSION}

During the middle age period, bio-wastes were dumped on streets, which allowed insects and rodents to cause hazardous epidemics and infectious illnesses. In the modern age, due to inadequate treatment methods of bio-wastes, numerous cases of diseases have been reported in developing countries. The overall interest of developed countries, with the assistance of Laws on Waste Disposal, is based on the management of bio-wastes and pollutants. The main purpose of the laws is to ensure and provide the conditions for the management of bio-wastes in a manner, which does not harm the health of humans and the ecosystem.

\section{A. Practical Solution for Waste Disposal and Pollution Management}

\section{1) Efficient Waste Management Demonstration}

As waste disposal trashcans, refuse drums and disposal baskets are issued to the street, parks, highways and roads, in the metropolis for proper public awareness regarding the management of bio-wastes, it is fundamental to consider the waste products that should be disposed. In that regard, efficient illustrations and demonstrations have to be indicated over the media, webs, radio jingle, and public announcements to create awareness and knowledge among the suburban and rural communities. Toxic and hazardous effects of ecological pollution could be determine by displaying unpleasant offensive and sight condition of local sewage and industrial bio-wastes, which are spewed into lakes, rivers, streams, canals, city drainage systems and gutters.

Bioaccumulations and bio-magnification of heavier metals normally in living systems, which leads to the pollution of heavy metals, malformation of organs, and death of living organisms. For the case of Italy, their environmental society estimates the years taken for bio-materials to decompose and degrade completely in the ecosystem. Fig 4 indicates some bio-materials and the time taken for these bio-materials to decompose. Before the process of decomposition is over, biomaterials cause inestimable pollution to land and sea environments. Biological components in the ecosystem incorporating the flow of nutrients in normal cycles and the relationship among biotic factors have been affected by toxic availability of bio-materials.

The demonstrations and illustrations vividly indicate futility of ineffective disposal of items into soil and water. If this takes about 300 years for an item to decompose, it thus means that the environment and health are at serious risk of pollution for a long period. The demonstrations in this case basically focus on the ecological damages and detrimental effects, which amount from ineffective disposal of non-bio-degradable bio-materials e.g. cans, tins, nylon bags and plastics. For the efficiency along these lines, engineering firms have to institute and initiate bonanzas and promotions, including declaring incentives for individuals collecting throw-away packs. They have to assist in environmental sanitation programs and cleanliness programs through the provision of product guidelines concerning the proper disposal of bio-materials.

a) Recyclable Bio-materials

Products can be made from the bio-materials, which can be recycled. This will resultantly lead to cost minimization and constitute to a tiny environment. Recyclable bio-materials represent the ones, which could be reprocessed and molded with the purpose of being reutilized for the same aim in the future. The process of recycling incorporates the aspect of using waste bio-materials and reprocessing, including reusage for bio-materials. This proved to be a promising technique for mineral resource conservation. If this is done in an organized way, the process of recycling can significantly minimize drainage on supplies and usage of novel mineral resources. It is appropriate for a product to be derived from living organisms, e.g. reclamation of organic bio-materials from sewage.

The process of recycling can significantly minimize the quantity of solid bio-wastes, which are deposited in landfills that have now become costly. Recycling minimizes air pollution, soil pollution and water pollution from the disposal of bio-wastes. It needs a refreshing and cleansing effect on the surrounding ecosystem. Many of the globe's phenomenal processes and natural cyclic schemes follow intrinsic bio-materials recycling procedures. Most of these procedures have proved to be fundamental to both biotic and abiotic components of the environment.

Forest litter and bio-wastes from aquatic floors are decomposed to add nutrients to the soil for the benefit of future plants' assimilation and absorption. The process of recycling is a perpetual and continuous process in the nature of organisms, soils and interrelations for refreshments and replenishment. Many living organisms have been seen to exhibit incredibly recycling energy with both their physical and biological microenvironments. Insects like termites, ants and dung insects are the best recycling agents for biological bio-wastes.

Earthworms are other considerable examples enhancing the process of decomposition. Naturally, worms consume these decomposing bio-wastes in the soil. Resultantly, they produce large amounts of worm casts, which add nutrients to the soil. Moreover, hazardous microbes available in decaying bio-wastes where worms feed, they die during the passage in gut. Due to the prevailing recycling and cleansing capacities, this is harnessed by the disposal of bio-wastes in industries, mostly in Australia. Worms feeding on human bio-wastes or manure are vital when it comes to agricultural and horticultural activities.

The two categories of recycling operations: external and internal can considered. Internal recycling represents the reuse in the processes of manufacturing, which represent the procedures followed during waste disposal. This form of recycling is common in the metallic industry. Copper tubing manufacture amounts in particular waste amounts in form of tube 
endings and trimmings, which represents remelted bio-materials. This form of recycling is evident in the distilling industry where mash is dried and processed into foodstuff for processing of organic fertilizers.

Another form of recycling operation i.e. external recycling represents the reclaiming of bio-materials for products, which is worn out and considered absolute. One of the examples of external recycling is the collection of old magazines and newspapers for the purpose of repulping and manufacturing into novel paper products e.g. tissue papers and light cardboards. Glass bottles and aluminum cans are some of the products that are recycled on a large scale. The bio-materials can be gathered by using three techniques: buyback centers that buy bio-materials, which have been grouped and brought by clients; dropoff centers, where clients can deposit bio-materials but not credited for them, and the curbside collection, where businesses and homes sort waste bio-materials before depositing them for collection through central agencies.

Community's choice of the manner and quantity of recycle is widely dependent on economic factors. Factors of affluence bio-materials encourage individuals' tendency to simply discard utilized bio-materials. Recycling is considered economically attractive whenever the reprocessing costs of bio-wastes and recycled bio-materials are less compared to processing costs of new bio-materials. A lot of developing nations will strive to consider this aspect. Governments can also make the required policies and plans for the production and introduction of the essential equipment and technologies to facilitate and enhance processes of managing bio-wastes.

Effective allocation of resources and funds will add effectively to these waste management systems. To minimize ecological hazards and pollution of plastic bags, an effective recycling procedure should be introduced as for the case of Australia. Elements of tapioca or cassava starch are being utilized to generate ecologically friendly and biodegradable bags. Evaluations indicate that after usage and when disposed, the bags can decompose in approximately three months.

\section{b) Recycling Bio-materials}

The reuse of bio-materials and its separation from bio-wastes is known as recycling. This incorporates the gathering, manufacture, processing and separation of novel products from the used bio-materials and items. Everything, which can be reused, is recycled. Without the advent of recycling in normal school life, it is not impossible to image an incorporated waste management scheme. There are recycling centers in the globe exploiting bio-materials from old things to create new ones; however, there are no centers in developing countries e.g. Nigeria. There are minimal centers such e.g. paper services where they potentially take centers for glass recycling and numerous glass bottles thrown yearly. With recycling, the following objectives can be accomplished.

- Saving bio-materials, (bio-materials sourced from natural resources and have them in limited quantity.

- Energy saving i.e. minimal energy loss in primary procedures, incorporating processes that follow and more energy is generated through burning bio-materials, which are never recycled.

- Ecological protection e.g. recycling protection of the ecology and waste material degradation

- Formation of novel tasks (processing in material recycling incorporating investment works and knowledge that creates jobs.

In terms of exploitation return, bio-materials can be recyclable or non-recyclable. Recyclable bio-materials can be utilized in recapturing production procedures after recycling has been done. On the other hand, non-recyclable biomaterials cannot be retrieved back to production procedure and are utilized in obtaining energy-burning warehouses in landfill. Hazardous bio-materials include those bio-materials, which harm the health of the environment and humans. Harmless bio-materials include those that are less harmful to the environment and humans. By the means of retrieving biomaterials in the process of reuse, recycling might be primary or secondary. In primary, recycling incorporate effective preparation of bio-materials utilized in obtaining the same products. On the other hand, secondary incorporate recyclable bio-materials, which are processed based on the application of novel technologies to probably efficiency.

\section{c) Recycling Plastic Bio-wastes}

Plastic bio-wastes are typically challenging to decompose. In case you are re-using, packaging bio-wastes and ecological pollution, saving raw resource and renewable energy. The most prevailing concern is due to unlimited usage of plastic products and remains dumping. There are various means of recyclable plastics; however, this boils down to similar operations. Technological procedures are composed of seven various phases: Collection of bio-wastes; Selection and identification; Milling; Rinsing; Spinning; Material Drying; and Storage.

Household plastic bio-wastes are placed in the same basket with the remaining bio-wastes, which brings up another issue. To mitigate this issue, containers are dependent on the type of plastic, paper or glass used. In many EU nations, the technique of sorting and collecting is already practiced. In early $21^{\text {st }}$ century, America had collected nearly 30 million plastic bio-wastes. As a result, reuse was essential. Yearly, Americans utilize approximately 90 kilograms of plastic of which $30 \mathrm{~kg}$ represents packaging. Germany on the other hand recycles approximately 900 tons of plastics that signify about $85 \%$ of the yearly volume of plastic bio-wastes.

UK recycles approximately 250 tons of plastic that is minor compared to the overall amount. From the early 20 s, plastic waste processing has advanced, with plastics regenerated to landfills [18]. This represents the residue, which cannot be processed. More attention is needed to create plastics, which will capable of breaking down with the assistance of microorganisms. These are known as biodegradables. Developing countries do not process plastic bio-wastes in a normal way; however, there is the best way to do so. Capabilities, which perform processing are also considered modest. 


\section{d) Recycling of Car Battery}

Significant amounts of unselected bio-wastes are being deposited at a landfill. Old batteries are being disposed of throughout the year in the landfill without any area of preparation. This amounts to fundamental contamination of the soil with lead acid and other inorganic components from batteries. To recycle old car batteries, it is fundamental to recycle and pre-allocate particular components and securely dispose bio-wastes occurring as residue after the process of recycling. The technological application of remaking old batteries is not certainly popular, although it has significant economic justification and fundamental implication on the ecosystem. Due to difficulties of gathering old batteries from landfills, settling all forms of bio-materials makes it challenging to make selections. Statistics indicate that we cast about a quarter of the overall number of batteries. One of the most essential raw resources from recycled battery is lead.

\section{e) Recycling of Motors at the End of their Lifecycle}

Motors are a product of high-end complexity. Some segments of cars are structured using different bio-materials; however, most dominant are cast using steel and iron. About $85 \%$ of the weight of motors can be recycled in the present recycling plants. The procedure of recycling cars is complex due to the wide-range bio-materials, which are a major part of cars. Glass, which is about $5 \%$ of the overall weight of cars, is not processed in manufacturing firms due to their complex chemical composition. However, they are chipped using constructions of concrete additives.

Fluids in motors (fuels, different forms of oil and coolants) constitute approximately $3 \%$ of the overall weight of motors. These are the fluids in the recycling process and the car can also complicate the entire process itself due to its chemical element and toxicity. Rubber is $6 \%$ of the overall weight of motors goes further to industrial manufacturing and has found applications to obtaining various products. A major risk posed to the environment due to industrial manufacturing is old car batteries. The parts of cars have to be handled separately and critically. At the moment, recycling technologies are applied and these differ in the way of categorizing bio-materials, which create cars. One example of technologies is optical separation and the second example utilizes multiple techniques e.g. gravitational, separation and mulching methods.

\section{f) Treat, Store and Dispose}

Different options are applicable for dangerous waste management schemes. According to D. Damigos, D. Kaliampakos and M. Menegaki in [19], most desirable schemes should focus on minimizing waste quantities at its source or recycling of biomaterials for production applications. Nonetheless, since reduction and recycling are desirable, they cannot be considered as ultimate solutions to problems of hazardous disposed bio-wastes. There will always be essential to treat, store, transport and dispose hazardous bio-wastes. These bio-wastes can be handled using physical, biological, thermal and chemical techniques.

Chemical techniques incorporate ion exchange, neutralization, reduction, oxidation and precipitation. Thermal techniques incorporate the application of high temperature organic bio-wastes, but extinguish them. Critical types of thermal equipment are used for the combustion of bio-wastes available in different forms such as solid, sludge and liquid. These includes the fluidized bed incinerators, multiple-hearth, rotary kiln, liquid-injection incinerator and furnace incinerators. One problem about these bio-wastes incinerators is the capacity for air pollution. The application of pollutionfree incinerators for minimizing and burning bio-wastes to ashes are fundamental when used as required. Ash end products of incinerators bio-wastes could be utilized as a component of fertilizers and ecologically-friendly manure for horticultural and agricultural purposes.

The treatment of bio-materials and organic bio-wastes e.g. those from petroleum industry, is considered an option. One of the techniques utilized in the process of treating hazardous bio-wastes biologically is land farming. With this method, bio-wastes are critically mixed with soils on tracts of land. Microorganisms, which metabolize bio-wastes, are incorporated alongside these materials. In some cases, genetically-engineered organisms are utilized. Forage and food crops are not grown on the same piece of lang. Through bioremediation, microbes can effectively be blamed for stabilization of hazardous bio-wastes on contaminated sites. Earthworms, insects and high plants are been considered as biological agents for the management of bio-wastes and the process of recycling.

Bioremediation is a rule and technique where biological resources are used for the process of restoring degraded sites to its original condition. Biological, thermal and chemical treatment techniques evaluated in this research transform the modular form of bio-materials. Physical treatment concentrates, reduces and solidifies waste volumes. Physical procedures incorporate filtration, flotation, sedimentation and evaporation. Another vital process considered is solidification, which is attained through the bio-waste encapsulation in concrete, plastic and asphalt.

Encapsulation generates solid mass of bio-materials, which are resistance to the process of leaching. Bio-wastes can be combined with fly ash, water and lime to create solid products and cement. All the techniques of recycling and treatment can be introduced and significantly utilized in the management of waste programs in developing countries. Programs and implementations need to serve both the rural and urban communities. Techniques for domestic bio-wastes management incorporate the usage of burying and pits. Typically, readily degradable bio-materials e.g. organic bio-materials of animal and plant parts, food bio-materials, agric produce and faecal products are suitable for these disposal methods.

In most instances, there are more beneficial effect burying provides to the soil health. It also enhances the decomposition of organs, formation of humus, cycling of nutrients and refertilization of soils. The users charge methods are an effective framework for ameliorating and combating the present collection of bio-wastes and weak disposal conditions in developing countries. In explaining how these approaches operate, highlighting the efficacy when parties 
cooperate as a team to accomplish healthier and cleaner ecosystem, which will indubitably contribute to global economic development is fundamental. It is suggested that developing countries have to consider paying a reasonable fee for services of waste disposal and collection. In this manner, private enterprises, households, and individuals assist and relieve the government concerning waste management programs. This practical approach could also be incorporated and introduced in rural waste management systems.

\section{CONCLUSION AND FUTURE DIRECTIONS}

In conclusion, developing countries should embrace the idea of using and promoting effective waste collection and disposal methods. The practical approaches detailed in this research have become fundamental to creating a cleaner and healthier ecosystem in developing nations. In that case, and with reference to prevailing factors, developing countries will do incredibly well to lead in the introduction and production of effective technologies, machine or equipment application, which incorporate waste disposal vehicles for effective waste management processes. Machines and equipment have to incorporate machines capable of generating recyclable bio-materials and machines, which could recycle utilized biomaterials to reusable ones. Enough information and training programs have to be disseminated and given and should focus on negative implications of bio-wastes on the ecosystem. Novel technologies, waste disposal approaches and their application should be communicated through lecturers, workshops, seminars and radio enhancement programs. This form of education and training is of utmost relevance for all the rural and urban communities in developing countries. Future research should project detailed instructions on how to maintain a clean environment in both rural and urban environments. The research regarding the practical training module should focus on effective environmental management techniques and waste disposal techniques to eliminate or reduce pollution, wastage of resources and erosion.

\section{References}

[1]. M. SCOTT, "Applications of risk assessment techniques to hazardous waste management", Waste Management \& Research, vol. 5, no. 2, pp. 173-181, 1987. Available: 10.1016/0734-242x(87)90050-4.

[2]. C. Rorres et al., "Contact tracing for the control of infectious disease epidemics: Chronic Wasting Disease in deer farms", Epidemics, vol. 23, pp. 71-75, 2018. Available: 10.1016/j.epidem.2017.12.006.

[3]. J. Humphries and B. Schneider, "Spinning the industrial revolution", The Economic History Review, vol. 72, no. 1, pp. 126-155, 2018. Available: 10.1111/ehr.12693.

[4]. J. Yang, "Urban Forestry in Challenging Environments", Urban Forestry \& Urban Greening, 2012. Available: 10.1016/j.ufug.2012.03.001.

[5]. ]N. MT, N. H and Y. MZ, "Health Care Waste Management and Sustainable Development Goals in Malaysia", Journal of Wastes and Biomass Management, pp. 18-20, 2019. Available: 10.26480/jwbm.01.2019.18.20.

[6]. Z. Ulfah and N. Roesa, "The Implementation of Polluter-Pays Principles on Marine Pollution Caused by Vessels in Indonesia (The Study of Oil Spill Cases)", Syiah Kuala Law Journal, vol. 4, no. 2, pp. 198-210, 2020. Available: 10.24815/sklj.v4i2.17847.

[7]. G. Bennett, "Storage and treatment of hazardous wastes in tank Systems", Journal of Hazardous Materials, vol. 22 , no. 1, p. 131 , 1989. Available: 10.1016/0304-3894(89)85034-4.

[8]. J. Kára, E. Janča and D. Herák, "Exploitation of anaerobic fermentation of bio-degradable wastes", Research in Agricultural Engineering, vol. 56, no. 1, pp. 8-17, 2010. Available: 10.17221/20/2009-rae.

[9]. U. Mohamed Faizal, R. Jayachitra, P. Vijayakumar and M. Rajasekar, "Optimization of inbound vehicle routes in the collection of bio-medical wastes", Materials Today: Proceedings, 2020. Available: 10.1016/j.matpr.2020.02.741.

[10]. "The Effects of Packaging on Customer Purchasing Decision. (Melcom Ghana Limited)", Journal of Marketing and Consumer Research, 2020. Available: $10.7176 / \mathrm{jmcr} / 65-02$.

[11]. P. Palaniswamy D, R. Ramesh G, S. Sri Pradeep M and R. Ranjith Raja S, "Investigation of Bio-Wastes and Methods for the Production of BioHydrogen - A Review", International Journal of Scientific Research, vol. 1, no. 5, pp. 60-62, 2012. Available: 10.15373/22778179/oct2012/20.

[12]. Z. Yuan, J. Shi, H. Wu, L. Zhang and J. Bi, "Understanding the anthropogenic phosphorus pathway with substance flow analysis at the city level", Journal of Environmental Management, vol. 92, no. 8, pp. 2021-2028, 2011. Available: 10.1016/j.jenvman.2011.03.025.

[13]. A. Omer, "Green Energy from Chemicals and Bio-Wastes", Research Journal of Biological Sciences, vol. 5, no. 9, pp. 581-600, 2010. Available: 10.3923/rjbsci.2010.581.600.

[14]. Y. GALKIN, "DEVELOPING THE STORM SEWAGE AND INDUSTRAL-STORM SEWAGE WASTEWATER PURIFYING SYSTEMS OF LARGE CITIES AND INDUSTRIAL ENTERPRISES", Urban construction and architecture, vol. 2, no. 4, pp. 64-70, 2012. Available: 10.17673/vestnik.2012.04.12.

[15]. K. Kim, "What's New About a New Methodology for Targeted Dumping? Impacts of the US Discretionary Practice on Margins of Dumping in Anti-Dumping Investigation", SSRN Electronic Journal, 2017. Available: 10.2139/ssrn.3190872.

[16]. M. Henstock, "Managing solid wastes in developing countries", Conservation \& Recycling, vol. 9, no. 1, p. 139, 1986. Available: 10.1016/03613658(86)90146-3.

[17]. J. Muiruri, R. Wahome and K. Karatu, "Assessment of methods practiced in the disposal of solid waste in Eastleigh Nairobi County, Kenya", AIMS Environmental Science, vol. 7, no. 5, pp. 434-448, 2020. Available: 10.3934/environsci.2020028.

[18]. K. WADA and H. UCHIDA, "Environmental impact of used plastic recycles", Journal of Advanced Science, vol. 19 , no. 34 , pp. 64-67, 2007. Available: $10.2978 /$ jsas.19.64.

[19]. D. Damigos, D. Kaliampakos and M. Menegaki, "How much are people willing to pay for efficient waste management schemes? A benefit transfer application", Waste Management \& Research, vol. 34, no. 4, pp. 345-355, 2016. Available: 10.1177/0734242x16633518. 